\title{
An evaluation of in-office flexible fiber- optic biopsies for laryngopharyngeal lesions
}

\author{
Francisco Lee ${ }^{1}$, Kristine A. Smith ${ }^{1}$, Shamir Chandarana ${ }^{1,2}$, T. Wayne Matthews ${ }^{1,2}$, J. Douglas Bosch",
} Steven C. Nakoneshny ${ }^{2}$ and Joseph C. Dort ${ }^{1,2^{*}}$ (i)

\begin{abstract}
Background: Operative endoscopy and flexible fiber-optic in-office tissue biopsy are common techniques to assess suspicious laryngopharyngeal lesions.

Methods: The primary outcome was the delay to the initiation of treatment. Secondary outcomes were delay to biopsy, histopathological diagnosis, and assessment at a multidisciplinary oncology clinic. A retrospective analysis was performed to assess the relative delays between these approaches to biopsy of laryngopharyngeal lesions.

Results: There were 114 patients in the study cohort; 44 in-office and 70 operative endoscopic biopsies). The mean delay from consultation to biopsy was 17.4 days for the operative endoscopy group and 1.3 days for the in-office group. The mean delay from initial otolaryngology consultation to initiation of treatment was 51.7 days and 44 . 6 days for the operative endoscopy and in-office groups, respectively.

Conclusion: In-office biopsy reduced the time from initial consultation to biopsy. The temporal gains via in-office biopsy did not translate into faster access to treatment. This outcome highlights the opportunity to improve access to treatment for patients with early diagnosis.
\end{abstract}

Keywords: Endoscopy, In-office biopsy, Larynx, Pharynx, Lesion

\section{Background}

Laryngopharyngeal lesions encompass a wide range of disease processes that includes benign lesions, local manifestations of systemic disease, inflammatory disorders and primary malignancies. In the United States, an estimated 61,700 new cases of oral cavity, pharynx, and larynx cancer will arise in 2016 and an estimated 13,190 deaths will occur from these cancers combined. [1] Given that early identification and treatment of head and neck cancers improves prognosis, [2-5] timely evaluation and diagnosis of suspicious lesions is important.

The larynx and lower pharynx are potentially challenging areas to assess and operative endoscopy is often necessary for thorough evaluation and biopsy of suspicious

\footnotetext{
* Correspondence: jdort@ucalgary.ca

${ }^{1}$ Section of Otolaryngology - Head and Neck Surgery, Department of Surgery, Cumming School of Medicine, University of Calgary, HRIC 2A02, 3280 Hospital Dr NW, Calgary, AB T2N 4Z6, Canada

${ }^{2}$ Ohlson Research Initiative, Arnie Charbonneau Cancer Institute, Cumming School of Medicine, University of Calgary, Calgary, Alberta, Canada
}

lesions. Operative endoscopy requires operating room (OR) time and general anesthesia and uses costly healthcare resources such as operating rooms and OR personnel. Complications arising from rigid instrumentation and general anesthesia, although uncommon, do occur, especially in high-risk patients with comorbid conditions.

One alternative, flexible fiber-optic nasopharyngoscopy, offers excellent visualization of the aerodigestive tract in an awake patient with low risk of complications. Newer technologies such as high-definition distal-chip nasopharyngoscopes provide excellent image quality, and side channels facilitate tissue biopsy with diagnostic accuracy comparable to that of operative endoscopy [6]. In a study by Castillo Farias et al. (2014), in-office biopsy of suspicious laryngeal lesions under fiber optic visualization offered a specificity of $81 \%$ and sensitivity of $100 \%$ compared to direct laryngoscopy [7]. Moreover, by performing an in-office biopsy as a first-line diagnostic step, and avoiding anesthetic and OR expenses, the

(c) The Author(s). 2018 Open Access This article is distributed under the terms of the Creative Commons Attribution 4.0 International License (http://creativecommons.org/licenses/by/4.0/), which permits unrestricted use, distribution, and 
authors reported a cost savings of $80 \%$ when compared to an operative biopsy for all patients presenting with suspicious lesions.

In addition to cost savings, it is important to understand the impact on time to diagnosis of different diagnostic approaches. The time differences between inoffice and operative approaches to the biopsy of suspicious laryngopharyngeal lesions remains relatively unknown. Furthermore, little is known about the impact of time to diagnosis on overall time to initiation of treatment. We therefore undertook a study to measure the differences in time to diagnosis and time to initiation of treatment in patients with laryngopharyngeal lesions who were undergoing operative endoscopy compared to a patient cohort undergoing in-office biopsy. Our hypothesis was that in-office biopsy would result in faster diagnosis and faster access to treatment.

\section{Methods}

\section{Study design}

We performed a retrospective case-control study comprising patients referred to a tertiary Head and Neck Oncology and Laryngology Clinic from January 1st, 2010 to December 31st, 2015. Cases were defined as patients undergoing in-office biopsies and the controls were defined as patients undergoing operative endoscopy requiring general anesthesia. This study was reviewed and approved by the Health Research Ethics Board of Alberta - Cancer Committee.

\section{Patients}

The study focused on patients presenting with oropharyngeal or laryngeal lesions requiring biopsy. These subsites were chosen because conventional access and biopsy of these lesions traditionally requires operative endoscopy. Patients older than 18 years of age with lesions visible on office endoscopy were eligible for inclusion. In-office biopsy patients were identified by review of billing codes and laryngology clinic records during the time period of interest and charts of potentially eligible patients were reviewed. Operative endoscopy patients were identified by querying a relational database (Otobase ${ }^{\circ}$, Seattle, WA) used to prospectively track all patients treated in our program. Patients with lesions accessible to a simple transoral biopsy without endoscopic assistance were not included. Patients unable to tolerate flexible endoscopy or who had a history of bleeding disorder were also ineligible for an in-office procedure. Patients with non-squamous cell carcinoma or a benign diagnosis were also excluded. The final cohort comprised 114 patients (44 in-office biopsy group and 70 operative endoscopy group) (Fig. 1).

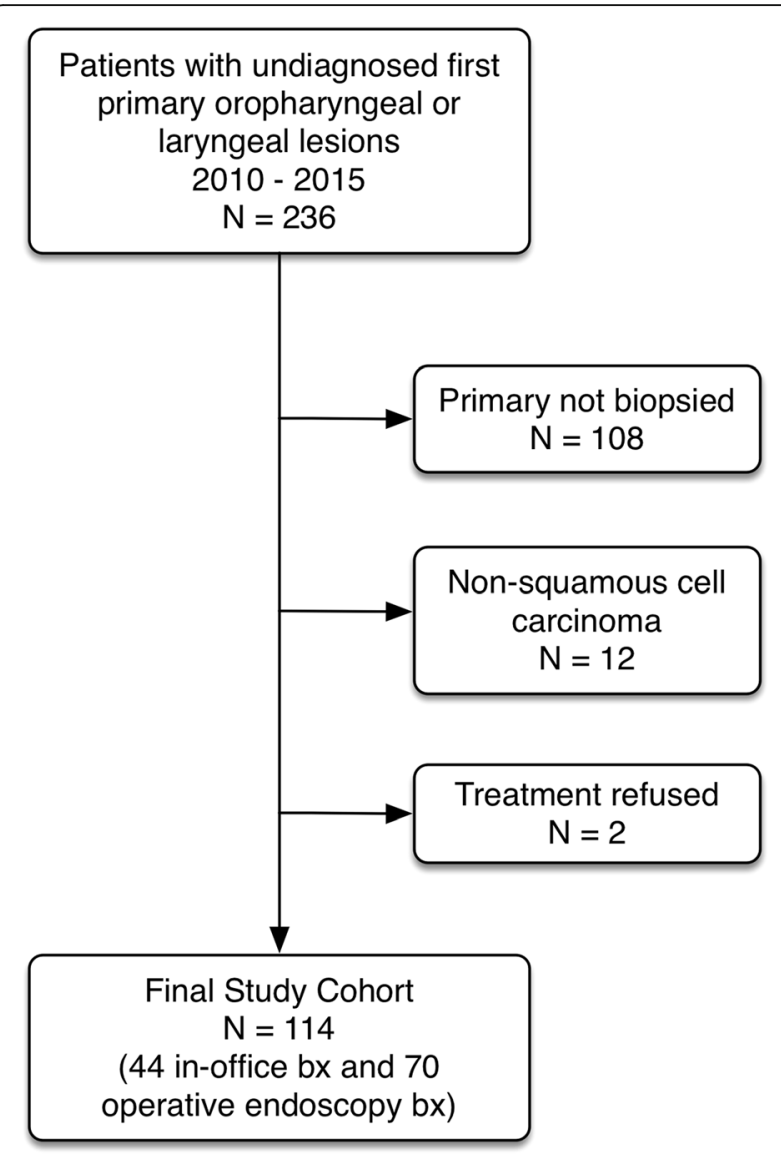

Fig. 1 Diagram showing composition of final study cohort

\section{Outcomes}

The primary outcome of interest was the time from the date of initial consultation by an otolaryngologist to the date of tissue biopsy. Secondary outcomes were the time from initial consultation to treatment, time from cancer diagnosis to multidisciplinary oncology consultation (MDOC), time from consultation to histopathological diagnosis and time from consultation to treatment.

\section{Statistical analysis}

Categorical variables were analyzed using either the Chi square or Fisher's exact test as appropriate. Continuous variables were analyzed using Students t-test or a Wilcoxon rank-sum test as appropriate. $P$-values of $<0.05$ were considered statistically significant for all tests. Statistical analyses were performed using Stata 14.2 (StataCorp LP, College Station, Texas, USA).

\section{Results}

One hundred fourteen patients were eligible for inclusion in the study (Fig. 1). The operative endoscopy biopsy group had 70 patients while the in-office biopsy 
group had 44 patients. Demographic information for the study population are summarized in Table 1 .

Patient ages ranged from 37 to 87 years, with a mean age of 62.3 years $(\mathrm{SD}=8.4)$. Patients were predominately male $(88 \%)$ and presented most commonly with clinical stage IV disease $(72 \%)$. The tongue base/vallecula were sampled most frequently (69\%). Chemoradiation therapy was the commonest modality of treatment (68\%). Subjects in the operative endoscopy biopsy group were younger, more likely to have a laryngeal primary and more likely to have fine needle aspiration (FNA) biopsy performed prior to biopsy of the primary cancer. There were no biopsy-related complications in either group.

Table 2 shows the time delays for different events. The mean time delay from consultation to biopsy was 17 . 4 days for the operative endoscopy biopsy group and 1 . 3 days for the in-office biopsy group $(p<0.0001)$. The time from consultation to tumor diagnosis was also significantly shorter in the in-office biopsy group (23 vs 7 . 5 days for the operative endoscopy biopsy and in-office biopsy groups respectively, $p<0.0001$ ). There was no difference in the time taken to generate a pathology report between the 2 groups. There were no differences in lag times from initial consultation to MDOC, from MDOC to treatment or from initial consultation to treatment suggesting that access to MDOC and treatment is a challenge regardless of how quickly a histopathological diagnosis is made. Further analysis revealed that MDOCs are triggered by any diagnosis of cancer, including an FNA. Fifty three percent of operative endoscopy biopsy patients had an FNA compared to fewer than $10 \%$ of in-office biopsy patients (Table 1). Because FNA was often performed prior to biopsy of the primary lesion, FNA patients entered the queue for MDOC sooner than patients without an FNA, potentially confounding this result.

\section{Discussion}

Diagnosis of suspicious laryngopharyngeal lesions is usually managed by otolaryngologists. Often suspicious lesions can be seen, and accessed, by the transoral route and in those cases a simple transoral biopsy can be performed in the office. However, many patients have lesions that are not accessible transorally and in those cases biopsy in the operating room becomes necessary. The adoption of flexible fiber-optic nasopharyngoscopes has made the assessment, biopsy, and diagnosis of suspicious lesions comparable to that of operative endoscopy biopsy with minimal risk and discomfort [6, 8]. This technique, when used in suitable patients, avoids a general anesthetic, reduces the need for operative resources, and offers the potential for earlier diagnosis and treatment.

In our case series, patients were able to receive an inoffice tissue biopsy 16 days earlier and a tumor tissue
Table 1 Demographics of the Study Population

\begin{tabular}{|c|c|c|c|}
\hline \multirow[t]{3}{*}{ Characteristic } & \multicolumn{2}{|c|}{ Biopsy Group } & \multirow[t]{3}{*}{$p$-value } \\
\hline & $\begin{array}{l}\text { Operative } \\
\text { Endoscopy }\end{array}$ & In-Office & \\
\hline & $n=70$ & $n=44$ & \\
\hline Age & & & 0.04 \\
\hline Mean years [SD] & $60.9[8.2]$ & $64.3[8.6]$ & \\
\hline Range & $37.1-81.3$ & $51.1-86.6$ & \\
\hline Gender & & & ns \\
\hline Male & 64 & 36 & \\
\hline Female & 6 & 8 & \\
\hline Clinical Stage & & & ns \\
\hline In-situ & 3 & 1 & \\
\hline । & 4 & 4 & \\
\hline$\|$ & 2 & 3 & \\
\hline III & 5 & 4 & \\
\hline IVA & 53 & 29 & \\
\hline IVB & 3 & 3 & \\
\hline Biopsy Site & & & ns \\
\hline Tongue base/vallecula & 51 & 28 & \\
\hline Larynx & 16 & 12 & \\
\hline Pharyngeal wall & 3 & 2 & \\
\hline Other & 0 & 2 & \\
\hline FNA Performed & & & $<0.001$ \\
\hline Yes & 37 & 4 & \\
\hline No & 33 & 40 & \\
\hline Treatment & & & ns \\
\hline Surgery alone & 8 & 4 & \\
\hline RT alone & 7 & 8 & \\
\hline Surgery and adjuvant RT & 4 & 0 & \\
\hline CRT & 48 & 30 & \\
\hline Surgery and adjuvant CRT & 1 & 1 & \\
\hline Neoadjuvant CRT and surgery & 2 & 1 & \\
\hline
\end{tabular}

$R T$ radiation therapy, $C R T$ chemoradiation therapy, ns non-significant Bold illustrates a statistically significant result

diagnosis 14.5 days sooner than a biopsy performed in the operating room. The availability of side-channel equipped office endoscopes makes in-office biopsy procedures feasible. Most patients are able to receive a tissue biopsy on the same day as their consultation or within a few days of presentation when side-channel forceps were needed. In addition to an earlier biopsy time, our data illustrate the safety of in-office endoscopeguided tissue sampling, with no procedure-related complications. This finding agrees with studies published elsewhere [6-9].

We were able to obtain tissue sufficient for histopathologic diagnosis in all cases where in-office biopsy was attempted. Analysis of healthcare costs avoided by in- 
Table 2 Time Delays to Clinical Events

\begin{tabular}{llll}
\hline Event & Biopsy Group & & p-value \\
\cline { 2 - 2 } & $\begin{array}{l}\text { Operative } \\
\text { Endoscopy }\end{array}$ & In-Office & \\
& $n=70$ & $n=44$ &
\end{tabular}

ENT Consultation to Biopsy

$\begin{array}{llll}\text { Mean days } & 17.4(13.5-21.3) & 1.3(-0.2-2.9) & <0.0001\end{array}$

ENT Consultation to Diagnosis

\begin{tabular}{|c|c|c|c|}
\hline $\begin{array}{l}\text { Mean days } \\
(95 \% \text { C.I.) }\end{array}$ & $23.0(18.8-27.2)$ & $7.5(5.5-9.4)$ & $<0.0001$ \\
\hline \multicolumn{4}{|c|}{ Pathology Delay (Biopsy to Diagnosis) } \\
\hline $\begin{array}{l}\text { Mean days } \\
\text { (95\% C.I.) }\end{array}$ & $5.6(4.9-6.4)$ & $6.1(4.9-7.3)$ & ns \\
\hline \multicolumn{4}{|c|}{ ENT Consultation to MDOC } \\
\hline $\begin{array}{l}\text { Mean days } \\
(95 \% \text { C.I.) }\end{array}$ & $23.4(19.4-27.4)$ & $19(16.0-22.0)$ & ns \\
\hline \multicolumn{4}{|c|}{ MDOC to Treatment } \\
\hline $\begin{array}{l}\text { Mean days } \\
(95 \% \text { C.I.) }\end{array}$ & $33(27.0-39.0)$ & $32(28.3-35.7)$ & ns \\
\hline \multicolumn{4}{|c|}{ ENT Consultation to Treatment } \\
\hline $\begin{array}{l}\text { Mean days } \\
(95 \% \text { C.I.) }\end{array}$ & $51.7(46.6-56.8)$ & $49.6(44.6-54.6)$ & ns \\
\hline
\end{tabular}

MDOC multidisciplinary oncology consultation, 95\% C.I. 95\% confidence interval, $n$ s non-significant

Bold illustrates a statistically significant result

office biopsy was beyond the scope of this study but other authors have reported cost outcomes. In a case series by Naidu et al. (2012), diagnostic in-office biopsy represented a $77 \%$ reduction in costs when compared to operative endoscopy biopsy for all patients presenting with laryngopharyngeal tumors [8]. Because all 44 patients in our in-office biopsy group received diagnostic biopsies, a referral to our pre-admission clinic for anesthesiology and internal medicine consultation, and scheduling for operative time and perioperative care were avoided. This likely resulted in an overall reduction in costs to our healthcare system.

Despite the shorter time delay to biopsy and potential for cost savings, some authors express concern regarding the diagnostic clarity of in-office tissue sampling. Richards et al. (2015) reported pathological variability between in-office and operative endoscopy biopsy of laryngeal lesions, with a relatively low sensitivity of $60 \%$ [9]. Of particular concern was the identification of invasive squamous cell carcinoma (SCC); just $15 \%$ of inoffice biopsies proved positive for SCC on initial inoffice evaluation. These authors therefore concluded that while in-office biopsies were a safe alternative to operative endoscopy biopsy, they were only moderately successful in identifying dysplastic lesions. Cohen et al. (2013) reported a similarly low sensitivity of $69 \%$ and false-negative rate of $33 \%$ when compared to direct operative endoscopy biopsy [10]. These values were comparable to results published in a subsequent study of laryngeal biopsies [11]. The authors therefore recommended that suspicious lesions returned as benign pathology or carcinoma in-situ proceed directly to microlaryngoscopy for histopathological verification. While these study results contrast with other published reports [6-8], they nevertheless highlight that variables such as biopsy size, depth, and patient tolerance are potential causes of false negative results. These factors need to be considered in the context of the entire clinical picture when determining patient candidacy for in-office biopsy.

Our study found that the time delays from diagnosis to MDOC, MDOC to treatment, and overall time to treatment were equivalent. This is in contrast to Lippert et al. (2014), in which the authors reported an average time saving of 24.6 days to treatment for patients who received a successful in-office biopsy [6]. In our series the delays from diagnosis to MDOC and treatment were similar between the in-office and operative biopsy groups and the reasons for this are likely multifactorial.

First, patient referrals for MDOC at our cancer center are triggered by a histopathological diagnosis of cancer. Incoming referrals are triaged and reviewed weekly by the Head and Neck Tumor Group. Patients with a diagnosis of cancer on FNA are offered an MDOC even in the absence of a proven primary. Operative endoscopy biopsy can therefore occur after the MDOC and this explains why there were no differences in lag times between the 2 groups.

Second, patients requiring radiation therapy need dental consultation as well as subsequent appointments for fitting of a custom head and neck mold prior to the initiation of radiation. This can take up to 2 weeks, or longer, to complete adding further delay to the initiation of therapy. Third, because 37 of the 70 patients in the operative endoscopy biopsy group initially presented to the MDOC with an FNA biopsy positive for neck malignancy, referral bias is likely present within our population. We therefore believe that a combination of system factors and referral bias explains why we did not see significant reductions in treatment delay in the in-office biopsy group.

Our study has some limitations, primarily its retrospective design and the potential for referral bias as noted above. Despite these shortcomings, the impact on time to biopsy and diagnosis is large and, we believe, real.

Delays in the initiation of treatment for head and neck carcinoma may lead to worse oncologic outcomes therefore strategies that reduce temporal delays ought to be identified and adopted. Our study shows that in-office flexible fiber-optic endoscope-guided biopsy represents a statistically and clinically significant method to expedite 
the identification of suspicious laryngopharyngeal lesions when compared to operative endoscopy biopsy. However, the overall time to the initiation of treatment, was not significantly impacted by in-office biopsy. We believe further study will clarify these uncertainties and identify opportunities for efficiency. Further study on the economic impact of in-office biopsy will also be helpful in understanding the true benefit of this procedure.

\section{Conclusions}

Our results show that in-office biopsy significantly reduces the time from initial presentation to diagnosis in patients with suspicious laryngopharyngeal lesions presenting to otolaryngologists. The temporal gains via in-office biopsy did not translate into faster access to treatment and we believe that the reasons for this are multifactorial. Further study is needed to quantify the economic impact on healthcare resource utilization.

\section{Abbreviations}

FNA: Fine needle aspiration; MDOC: Multidisciplinary oncology consultation; OR: Operating room; SCC: Squamous cell carcinoma

\section{Acknowledgements}

We gratefully acknowledge the Ohlson Research Initiative for supporting this project.

\section{Funding}

Support for this research was provided by a grant from the Ohlson Research Initiative. The funder had no role in study design, or collection, analysis, interpretation of data, or in the writing of the manuscript.

\section{Availability of data and materials}

The datasets generated and/ analyzed during this study available from the corresponding author on reasonable request.

\section{Authors' contributions}

FL and KS participated in data analysis, interpretation of the data, and participated in writing and preparation of the manuscript. JCD developed the study concept and design, acquired the data, was involved in the analysis and interpretation, and co-wrote and critically revised the manuscript. SCN assisted with study design, performed data analysis and interpretation of the data, and helped draft and critically revise the manuscript. SPC, TWM, and JDB assisted in the interpretation of the data and critically revised the manuscript. All authors give final approval for the manuscript to be published and agree to be accountable for it.

\section{Ethics approval and consent to participate}

This study was reviewed and approved by the Health Research Ethics Board of Alberta - Cancer Committee (HREBA.CC-16-0646).

\section{Competing interests}

The authors declare that they have no competing interests.

\section{Publisher's Note}

Springer Nature remains neutral with regard to jurisdictional claims in published maps and institutional affiliations.

Received: 15 December 2017 Accepted: 17 April 2018

Published online: 09 May 2018

\section{References}

1. SEER Cancer Stat Fact Sheet [http://seer.cancer.gov/statfacts/].

2. van Harten MC, Hoebers FJ, Kross KW, van Werkhoven ED, van den Brekel MW, van Dijk BA. Determinants of treatment waiting times for head and neck cancer in the Netherlands and their relation to survival. Oral Oncol. 2015;51:272-8.

3. Pitchers M, Martin C. Delay in referral of oropharyngeal squamous cell carcinoma to secondary care correlates with a more advanced stage at presentation, and is associated with poorer survival. $\mathrm{Br} J$ Cancer. 2006;94:955-8.

4. Stefanuto P, Doucet JC, Robertson C. Delays in treatment of oral cancer: a review of the current literature. Oral Surg Oral Med Oral Pathol Oral Radiol. 2014;117:424-9.

5. Jensen AR, Nellemann HM, Overgaard J. Tumor progression in waiting time for radiotherapy in head and neck cancer. Radiother Oncol. 2007;84:5-10.

6. Lippert D, Hoffman MR, Dang P, McCulloch TM, Hartig GK, Dailey SH. Inoffice biopsy of upper airway lesions: safety, tolerance, and effect on time to treatment. Laryngoscope. 2015;125:919-23.

7. Castillo Farias F, Cobeta I, Souviron R, Barbera R, Mora E, Benito A, Royuela A. In-office cup biopsy and laryngeal cytology versus operating room biopsy for the diagnosis of pharyngolaryngeal tumors: efficacy and costeffectiveness. Head Neck. 2015;37:1483-7.

8. Naidu H, Noordzij JP, Samim A, Jalisi S, Grillone GA. Comparison of efficacy, safety, and cost-effectiveness of in-office cup forcep biopsies versus operating room biopsies for laryngopharyngeal tumors. J Voice. 2012;26:604-6.

9. Richards AL, Sugumaran M, Aviv JE, Woo P, Altman KW. The utility of officebased biopsy for laryngopharyngeal lesions: comparison with surgical evaluation. Laryngoscope. 2015;125:909-12.

10. Cohen JT, Safadi A, Fliss DM, Gil Z, Horowitz G. Reliability of a transnasal flexible fiberoptic in-office laryngeal biopsy. JAMA Otolaryngol Head Neck Surg. 2013;139:341-5.

11. Cohen JT, Benyamini L. Transnasal flexible Fiberoptic in-office laryngeal biopsies-our experience with 117 patients with suspicious lesions. Rambam Maimonides Med J. 2014;5:e0011.

\section{Ready to submit your research? Choose BMC and benefit from:}

- fast, convenient online submission

- thorough peer review by experienced researchers in your field

- rapid publication on acceptance

- support for research data, including large and complex data types

- gold Open Access which fosters wider collaboration and increased citations

- maximum visibility for your research: over $100 \mathrm{M}$ website views per year

At BMC, research is always in progress.

Learn more biomedcentral.com/submissions 